\title{
Formulations Containing Curcumin or Trans-Resveratrol Increase Dermal Thickness in Rats Submitted to Chemical Peeling
}

\section{Gisele Mara Silva Gonçalves*, Pedro Paulo Barros, Gustavo Henrique da Silva, Erica Mendes dos Santos, Amanda Figlia Minutti}

Faculty of Pharmaceutical Sciences, Pontifical Catholic University of Campinas, Campinas, Brazil

Email: *gmsg@puc-campinas.edu.br

How to cite this paper: Gonçalves, G.M.S., Barros, P.P., da Silva, G.H., dos Santos, E.M. and Minutti, A.F. (2017) Formulations Containing Curcumin or Trans-Resveratrol Increase Dermal Thickness in Rats Submitted to Chemical Peeling. Journal of Cosmetics, Dermatological Sciences and Applications, 7, 14-26.

https://doi.org/10.4236/jcdsa.2017.71002

Received: November 15, 2016

Accepted: February 3, 2017

Published: February 6, 2017

Copyright $\odot 2017$ by authors and Scientific Research Publishing Inc. This work is licensed under the Creative Commons Attribution International License (CC BY 4.0).

http://creativecommons.org/licenses/by/4.0/

\begin{abstract}
Plant-derived substances such as curcumin and trans-resveratrol, both of which have anti-inflammatory properties, may have a beneficial effect on human skin. The present study analyzed the effects of topical formulations containing curcumin or trans-resveratrol on the recovery and rejuvenation of skin after chemical peeling. The study was performed on rats, randomly divided into seven groups of six animals each. Superficial peeling was performed using a $50 \%$ glycolic acid gel, which was applied to the dorsal region of each animal. Rats were then treated with the experimental formulations for 15 days. On the sixteenth day, skin samples were taken and mounted on slides for histological analysis. Statistical analysis showed that the formulation containing transresveratrol led to increased dermal and epidermal thickness, while the formulation containing curcumin had no effects on epidermal thickness. The increased epidermal thickness may reflect greater skin vitality, although this was not directly evaluated. The increase in dermal thickness may be attributed to greater collagen production, which may increase skin firmness and elasticity, and lead to skin rejuvenation as well as wrinkle reduction. Formulations containing curcumin or trans-resveratrol may have potential for the topical treatment after peeling and of sensitive skin, in addition to being used for their antiaging properties.
\end{abstract}

\section{Keywords}

Curcumin, Resveratrol, Peeling, Histological Analysis

\section{Introduction}

Chemical peeling is a dermatological treatment for aesthetic improvement of the 
skin which can also remove blemishes, wrinkles, thin lines and acne scars [1] [2]. Chemical peeling can be classified as superficial, medium, or deep depending on the concentration, $\mathrm{pH}$, and duration of exposure to the peeling agent. Superficial peeling leads to desquamation, increased epidermal enzyme activity, epidermolysis and exfoliation [3]. The inflammatory process induced by chemical peeling can have uncomfortable side effects, such as pain, stinging and irritation, which may be unacceptable to some patients [4]. As a result, topical anesthetics such as lidocaine are often used before the procedure [5].

In the post-peeling period, patients often report stinging and desquamation of the skin exposed to the acid. The procedure also increases skin exposure, so that patients must avoid all sunlight and use sunscreen even when indoors to prevent blemishes in the period intermediately following treatment [6].

If successful, chemical peeling produces visible improvement in skin conditions. However, complications such as scar formation have also been known to occur. Heng [7] studied the effects of a gel containing $12 \%$ curcumin on the healing of burns and ultraviolet (UV) light injury. The treatment contributed to the prevention of hypertrophic scars after surgery, but was only effective when applied in the early stages of scar tissue formation.

Curcumin (diferuloylmethane) is obtained from Curcuma longa, a plant of the Zingiberaceae family. The compound has been described as a potent antioxidant and anti-inflammatory agent [8] [9]. Pharmacologically, curcumin has been found to be safe. Human clinical trials indicated no dose-limiting toxicity when administered at doses up to $10 \mathrm{~g} /$ day [10].

In 2011, Hamzah [11] analyzed the anti-inflammatory effects of a gel containing curcumin extract on carrageenan-induced paw edema in albino rats. The study found that curcumin produced a $30 \%$ reduction in edema.

According to Huang et al. [12], topical curcumin is a potent inhibitor of skin tumors induced on rats. Kumar et al. [13] found that curcumin suppresses proinflammatory adhesion molecules, and suggested its use in the treatment of atherosclerosis, septicemia, inflammation, and tumor metastasis.

Okunieff et al. [14] evaluated the protective effects of curcumin on radiationinduced cutaneous toxicity in rats. In this study, curcumin was given intragastrically or intraperitoneally five days before and/or after exposure to radiation. The treatment led to significant reductions in the expression of cytokine mRNA (e.g. IL-6 IL-1, IL-18) in cutaneous tissues, suggesting that curcumin has a protective effect against radiation-induced cutaneous damage. Due to the beneficial effects of curcumin on the modulation of radiation-induced skin toxicity, the authors also suggested it may be applicable to patients receiving clinical radiation therapy, such as that used to treat breast, head and neck cancers.

Although the purpose of the inflammatory process is to protect the organism, prolonged inflammation can contribute to tumor formation. As such, curcumin may help prevent cancer development, as suggested by Lin and Lin [9], as well as other conditions triggered by inflammatory processes, such as atherosclerosis and cancer [5] [15]. These authors define curcumin as a nutraceutical substance 
with anti-inflammatory properties, highlighting the evidence of its antioxidant and anti-inflammatory potential, as well as its potential application to the treatment of conditions such as cancer, cardiovascular disease, Alzheimer's, rheumatoid arthritis and metabolic syndrome. Given the low bioavailability of curcumin in the body, Patel et al. [16] developed a system for the transdermal delivery and systemic distribution of curcumin.

Resveratrol (3,4,5-trihydroxystilbene) is a polyphenolic compound found in the skin of red fruits which has potent anti-inflammatory effects [17]. Some authors suggest that it may play a role in the chemoprevention of cancer [18], and that it may be involved as an antioxidant in the prevention of cardiovascular disease and other conditions [19] [20] [21] [22]. The topical application of a formulation containing $1 \%$ resveratrol was found to have a protective effect against damage induced by repetitive UV irradiation [23].

The penetration of polyphenols into skin is limited by their poor solubility. As a result, several attempts have been made to develop formulations to increase its skin penetration [24]. Abla and Banga [25] evaluated the penetration of antioxidants into pig-ear skin, and found decreasing concentrations of catechin, resveratrol and curcumin in the stratum corneum. Approximately $90 \%$ of the total amount of polyphenols in the skin was retained in the stratum corneum, with only $10 \%$ penetrating the underlying layers of skin. Polyphenols interact with membrane phospholipids, forming a depot on the skin.

Alonso et al. [26] evaluated the skin penetration of resveratrol, and found that only $3.4 \%$ of the total amount administered was retained in the stratum corneum, while $0.5 \%$ was retained in the epidermis. Ravagnan et al. [27], studied resveratrol and polydatin, its natural precursor, and suggested that the combined use of these substances may have an increased cytoprotective effect under stress.

In light of these observations, the aim of the present study was to analyze the effects of formulations containing curcumin or trans-resveratrol on the recovery and rejuvenation of skin after chemical peeling.

\section{Methods}

This study was approved by the Animal Research Ethics Committee of the Catholic University of Campinas (054/13).

\section{Animals}

Forty-two 40-day-old male Wistar rats (weight: $200 \mathrm{~g} \pm 10 \mathrm{~g}$ ) were obtained from the animal facility of the Department of Life Sciences (Pontifícia Universidade Católica de Campinas, SP, Brazil). Animals were kept under controlled temperatures $\left(23^{\circ} \mathrm{C} \pm 1^{\circ} \mathrm{C}\right)$ and a 12-hour light/dark cycle throughout the experiment. Rats were fed commercial chow (Nuvilab) and water ad libitum.

\section{Formulations}

A formulation containing the following ingredients was prepared: $3.5 \mathrm{~g}$ of a synthetic polymer used as a gelling agent for aqueous systems (Ammonium 
Acryloyldimethyltaurate/VP Copolymer), $5 \mathrm{~g}$ humectant (Propylene Glycol), 0.8 $\mathrm{g}$ of a preservative blend (Phenoxyethanol, Methylparaben, Ethylparaben, Propylparaben, Butylparaben, Isobutylparaben), $0.01 \mathrm{~g}$ chelating agent (Disodium EDTA), and purified water up to $100 \mathrm{~g}$. To this basic formulation were added $0.01 \mathrm{~g}$ SigmaTM curcumin and/or $0.7 \mathrm{~g}$ trans-resveratrol (PharmaNostra, Brazil). As a result, three formulations were produced, containing curcumin, transresveratrol and curcumin + resveratrol, respectively.

The chemical peeling formulation was composed of $2.0 \mathrm{~g}$ Hydroxyethylcellulose, $50 \mathrm{~g}$ glycolic acid, $5 \mathrm{~g}$ humectant (Propylene Glycol), $0.8 \mathrm{~g}$ of a preservative blend (Phenoxyethanol, Methylparaben, Ethylparaben, Propylparaben, Butylparaben, Isobutylparaben), and purified water up to $100 \mathrm{~g}$.

\section{Chemical Peeling}

Animals were randomly distributed into seven groups containing six rats each (Table 1).

Rats were anesthetized with intraperitoneal ketamine, and dorsal hairs were removed to expose $2 \mathrm{~cm}^{2}$ of skin. Groups 2, 5, 6 and 7 were administered a gel containing 50\% glycolic acid [28]. After 5 minutes, the area was cleaned with saline and gauze, and a gel containing 20\% lidocaine was administered. After 24 hours, one of the three formulations was applied manually to the dorsal region of each animal. This procedure was repeated once a day for 15 days.

On the 16th day, animals were euthanized with ketamine/xylazine. Skin specimens were taken from the exposed location, and fixed in $10 \%$ buffered formaldehyde.

\section{Histological Processing}

Skin tissue fragments were cut into $7 \mu$-thick slices and stained with hematoxylin-eosin (HE) and Masson's Trichrome (MT). Images were captured using a photomicroscope (Nikon Eclipse E200TM) connected to a camera (Nikon Colpix 4500TM).

Table 1. Experimental groups.

\begin{tabular}{|c|c|c|}
\hline Group 1 & Negative control & No topical treatment \\
\hline Group 2 & Peeling control & Peeling \\
\hline Group 3 & Curcumin & $\begin{array}{l}\text { Once-daily administration of } \\
\text { curcumin formulation }\end{array}$ \\
\hline Group 4 & Resveratrol & $\begin{array}{l}\text { Once-daily administration of } \\
\text { trans-resveratrol formulation }\end{array}$ \\
\hline Group 5 & Post-peeling curcumin & $\begin{array}{l}\text { Peeling, followed by once-daily administration } \\
\text { of curcumin formulation }\end{array}$ \\
\hline Group 6 & Post-peeling resveratrol & $\begin{array}{l}\text { Peeling, followed by once-daily administration } \\
\text { of trans-resveratrol formulation }\end{array}$ \\
\hline Group 7 & Post-peeling curcumin + resveratrol & $\begin{array}{l}\text { Peeling, followed by once-daily administration } \\
\text { of curcumin }+ \text { trans-resveratrol formulation }\end{array}$ \\
\hline
\end{tabular}


The histological features of the skin, as well as epidermal and dermal thickness, were analyzed on 20 randomly selected images (total of 120 images per group). The AreaMed ${ }^{\oplus}$ software (Application to calculate areas from digital images, it calculates the areas for color identification or delimitation of the object to be measured) was used to determine the area of dermis (MT stain) and epidermis (HE stain) and therefore the result was achieved in the area of each layer unit $\left(\mu \mathrm{m}^{2}\right)$. In this analysis, the length is kept constant and the height is variable depending on the thickness of the layer, so it is considered that the larger the calculated area, the greater the thickness of the layer analyzed.

\section{Statistical Analysis}

Epidermal and dermal areas were analyzed using Graph Pad PRISM ${ }^{\mathrm{TM}}$ 3.0. The groups were compared using analysis of variance (ANOVA) followed by Bonferroni post-hoc tests $(\mathrm{p}<0.05)$.

\section{Results and Discussion}

The gel formulation used as vehicle for curcumin and trans-resveratrol was developed with common and simple substances that have been widely used in topical products. Whereas the patient should apply the product on your own skin, the formulation allows the selection of the correct location, i.e., the skin of the face. This study did not use placebo as this was considered unnecessary, given that none of its components has an effect on epidermal cell renewal or the collagen content of the dermis at used concentrations.

The choice of the skin of Wistar rats for this study was carried out based on previous studies on peeling which using damage induced by laser resurfacing procedure [29]. No evidence of irritation or erythema was observed in most animals following the application of $50 \%$ glycolic acid gel, confirming that the procedure was not aggressive. Scabs did not form on the treatment site, and there was no evidence of angiogenesis or granulation tissue formation. Microscopic analysis (illustrated in Figure 1) revealed no evidence of increased thickness of the basal, spinous and granular layers in groups 2 through 7 as compared to group 1 (control). However, there appeared to be an increase in the size of basal cells-but not their nuclei-especially on slides made from specimens treated with trans-resveratrol.

Epidermal thickness (obtained in area unit $-\mu \mathrm{m}^{2}$ ) (Figure 2) did not statistically differ between the peeling and control groups. Rodrigues and Maia Campos [30] reported an increase in the epidermal thickness of hairless mouse skin after 15 days of treatment with glycolic acid. Therefore, it is possible that the chemical peeling performed in the present study was not sufficiently intense to produce a statistically significant increase in epidermal thickness.

No evidence of adverse reactions or animal suffering was observed over the course of treatment, confirming the safety of experimental procedures. According to Yokomizo et al. [31], glycolic acid can induce epidermolysis for a period ranging from three to seven minutes. Song et al. [32] evaluated the effects of 

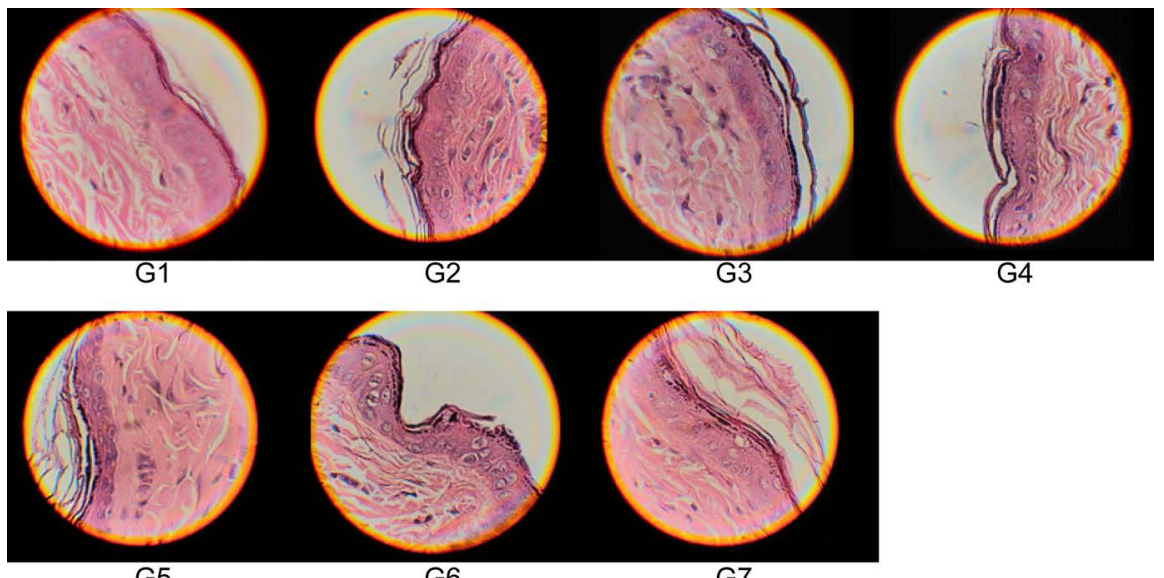

G5

G6

G7
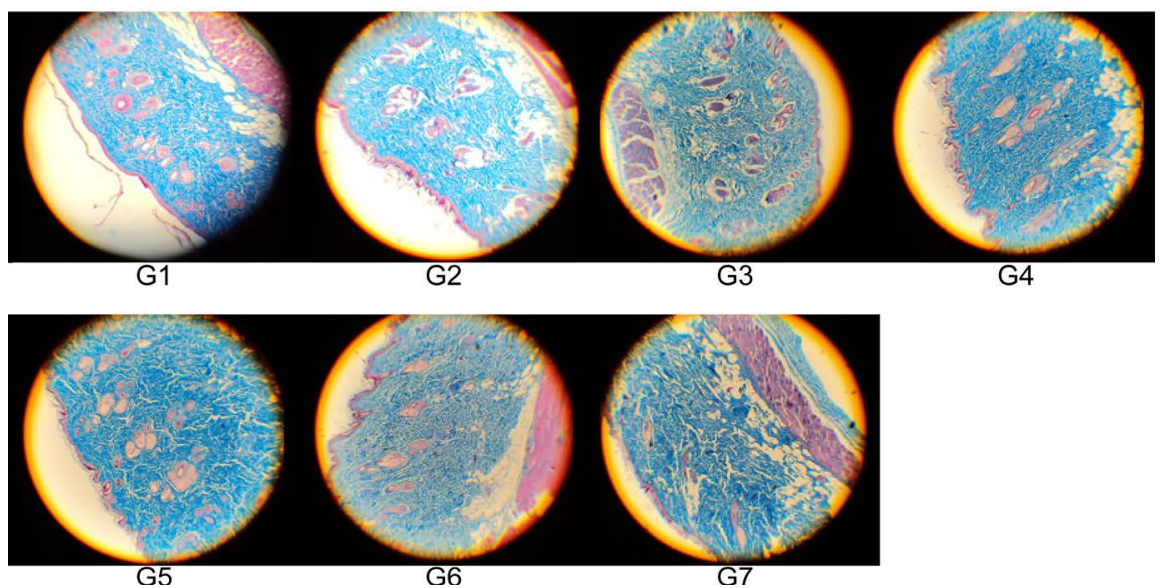

Figure 1. Photomicrographs of skin. Hematoxylin-eosin (100× magnification) and Masson's Trichrome (10× magnification). Control (G1), Peeling (G2), Curcumin (G3), Transresveratrol (G4), Post-peeling curcumin (G5), Post-peeling trans-resveratrol (G6) and Post-peeling curcumin + resveratrol (G7).

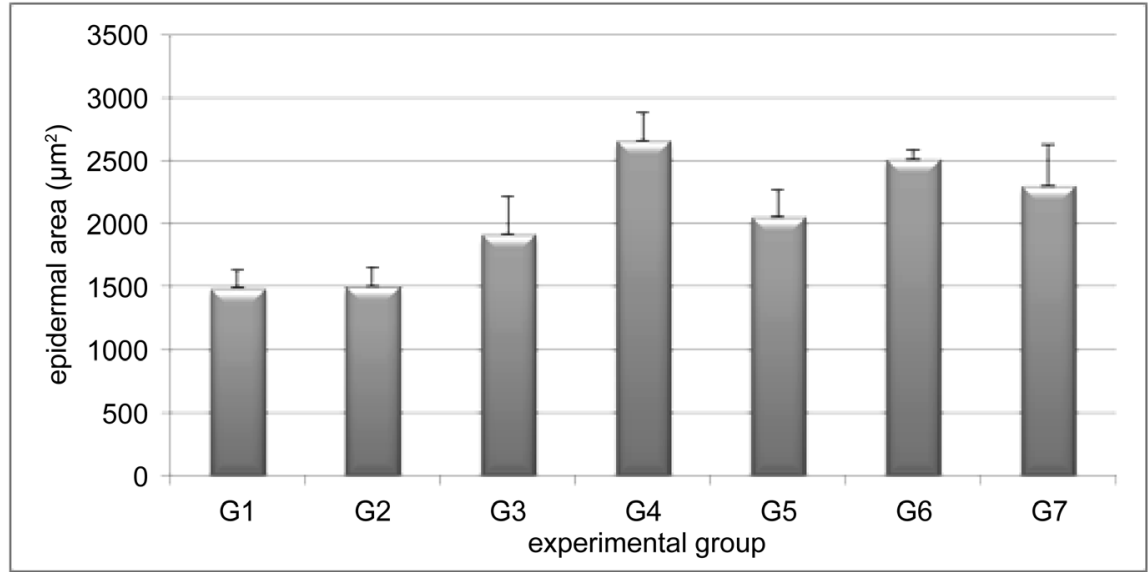

Figure 2. Rats epidermal thickness in unit area (HE Stain). Control (G1), Peeling (G2), Curcumin (G3), Trans-resveratrol (G4), Post-peeling curcumin (G5), Post-peeling transresveratrol (G6) and Post-peeling curcumin + resveratrol (G7). Analysis of variance followed by Bonferroni post-hoc tests. Those comparisons with $\mathrm{p}<0.05$ were: $\mathrm{G} 1$ vs $\mathrm{G} 4$ ( $\mathrm{p}<$ 0.001); G1 vs G6 (p < 0.001); G1 vs G7 (p<0.001); G2 vs G4 (p < 0.001); G2 vs G6 (p < 0.001); G2 vs G7 ( $\mathrm{p}<0.001)$; G3 vs G4 ( $\mathrm{p}<0.01)$; G3 vs G4 ( $\mathrm{p}<0.05)$; G4 vs G5 ( $\mathrm{p}<$ $0.05)$. 
superficial chemical peeling using $50 \%$ glycolic acid, applied to the forearm of a sample of volunteers for a duration of three minutes. The authors reported an increase in transepidermal water loss (TEWL) in the first hours following the procedure, and noted the presence of erythema up to 3 days later. These findings suggest that the skin barrier function is damaged by glycolic acid peeling. However, the TEWL returned to normal within 24 hours of the procedure. In the present study, the assessment was performed 15 days after chemical peeling, by which time the skin had already recovered its barrier function.

Epidermal thickness was only found to be significantly increased in groups treated with trans-resveratrol (groups 4, 6 and 7) as compared to the control group. This was not observed in animals treated with curcumin. The increased epidermal thickness suggests that the trans-resveratrol may have interfered with the epidermal renewal process which follows chemical peeling.

The increased dermal thickness (also obtained in area unit $-\mu \mathrm{m}^{2}$ ) in groups treated with the aforementioned formulation was revealed by histological analysis, and is shown in Figure 3. The dermis was homogeneous and had a normal appearance across all groups, though it was thicker in groups 3 through 7 .

Statistical analysis revealed no significant differences between the Peeling and control groups. Different results may have been obtained with the use of a more aggressive peeling program (with a higher acid concentration, a longer duration of exposure, and a greater number of applications), such as that performed by Han et al. [2], who observed an increase in dermal thickness in rats submitted to more aggressive chemical peeling.

The remaining groups showed an increase in dermal thickness. Since the analysis was performed on MT-stained slides (whose purpose is to identify collagen fibers-blue), the increase may be attributable to greater collagen production,

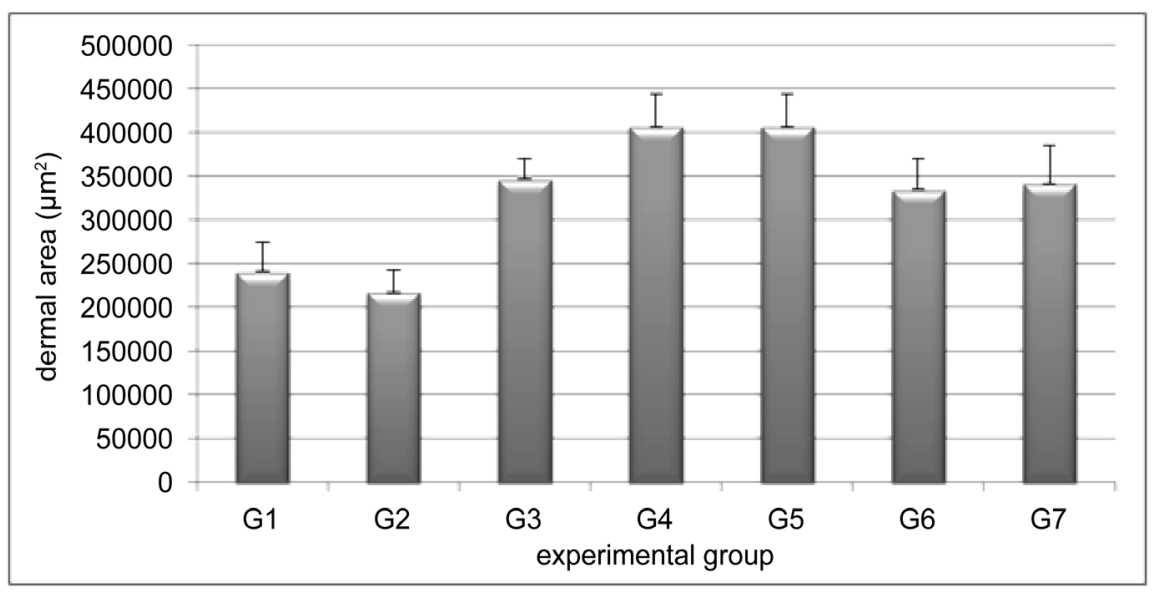

Figure 3. Rats dermis thickness in unit area (MT Stain): Control (G1), Peeling (G2), Curcumin (G3), Trans-resveratrol (G4), Post-peeling curcumin (G5), Post-peeling transresveratrol (G6) and Post-peeling curcumin + resveratrol (G7). Analysis of variance followed by Bonferroni post-hoc tests. Those comparisons with $\mathrm{p}<0.05$ were: G1 vs G3 ( $\mathrm{p}<$ 0.05); G1 vs G4 ( $\mathrm{p}<0.001) ; \mathrm{G} 1$ vs G5 ( $\mathrm{p}<0.001)$; G1 vs G7 ( $\mathrm{p}<0.05)$; G2 vs G3 (p < $0.01) ; \mathrm{G} 2$ vs $\mathrm{G} 4(\mathrm{p}<0.001) ; \mathrm{G} 2$ vs $\mathrm{G} 5(\mathrm{p}<0.001)$; G2 vs $\mathrm{G} 6(\mathrm{p}<0.01) ; \mathrm{G} 2$ vs $\mathrm{G} 7$ ( $\mathrm{p}<$ $0.01)$. 
which leads to increased firmness and recovery, as well as wrinkle reduction. However, the Post-peeling curcumin group showed a greater increase in dermal thickness than the Curcumin group. These findings suggest that the chemical peeling facilitated cutaneous penetration, since curcumin is lipophyllic and tends to be retained on the epidermal surface [33]. Therefore, the removal of the corneum may allow the curcumin to penetrate more deeply and act in a more efficient way. According to this hypothesis, peeling had a positive effect on the effects of curcumin.

This corroborates the findings of Panchatcharam et al. [34], who investigated the effects of topical curcumin on cutaneous incisions in rats. In the study in question, topical treatment with curcumin had a positive effect on all stages of healing, including collagen synthesis and maturation, wound contraction and epithelialization.

In the present study, the resveratrol and post-peeling resveratrol groups showed increased dermal thickness as compared to the control group. In this case, chemical peeling did not appear to interfere with the effects of the formulation.

The post-peeling curcumin + resveratrol group showed a thicker dermis than the control group. However, the combination of both formulations had no additive effects on dermal thickness.

Increases in dermal thickness are attributed to greater collagen deposition, as observed in previous studies [2] [35]. Collagen is responsible for skin firmness and elasticity, the increase of which is a major objective of chemical peeling. Therefore, the use of formulations containing curcumin or trans-resveratrol could be recommended by dermatologists to maximize the benefits obtained after chemical peeling.

According to Prakash and Majeed [36], skin aging may be triggered by inflammation, and as such, topical formulations containing curcumin may have significant therapeutic applications, since, as noted by several authors, curcumin has both antioxidant and anti-inflammatory properties.

The anti-inflammatory effects of curcumin can be attributed to its role as an inhibitor of Nuclear Factor Kappa B (NF- $\kappa$ B), an important transcription factor in the inflammation process. NF- $\kappa \mathrm{B}$ contributes to the increased transcription of COX-2 and other pro-inflammatory genes, such as inducible nitric oxide synthase (iNOS). Curcumin also increases the accumulation of glutathione, an important intracellular antioxidant, and inhibits the activity of inflammatory enzymes [37].

In another recent study, the topical use of curcumin proved to be an effective treatment for animal models of psoriasis, as well as for human volunteers. These findings provide further evidence of the immunomodulating and anti-inflammatory properties of curcumin, as well as its role in the inhibition of COX and phosphorylase kinase ( $\mathrm{PhK})$ [38].

Curcumin is orange in color, and is not commonly used in topical formulations. This may be why few studies in the literature have studied its effects on 
skin. However, patients who experience uncomfortable symptoms, such as desquamation, after chemical peeling-especially of the intermediate of deep variety-may not mind the color of the formulation as long as it causes symptom relief. Furthermore, the color of the formulation can always be changed using whitening agents such as titanium dioxide, which is also widely used as a photoprotective agent.

While the skin penetration of trans-resveratrol and other antioxidants upon topical application have already been studied by authors such as Abla and Gamba [25], these investigations used pig ear skin as a model for human skin penetrability. The authors found that catechin showed the greatest accumulation in the stratum corneum, followed by trans-resveratrol and retinol. Approximately $90 \%$ of polyphenols were retained in the stratum corneum, with only $10 \%$ penetrating into deeper layers of the skin. These findings have been corroborated by other studies of the cutaneous penetration of trans-resveratrol. A separate investigation found that $3.4 \%$ of the total amount of trans-resveratrol applied to the skin could be recovered from the stratum corneum, and only $0.5 \%$ from the epidermis [26].

Antioxidants such as vitamins $\mathrm{C}$ and $\mathrm{E}$ have a positive effect on fibroblasts, increasing collagen production [39]. Previous studies have found that transresveratrol inhibits collagen production in cultures of intestinal fibroblasts [40] [41]. When evaluating the effects of trans-resveratrol on the treatment of keloids, Ikeda et al. [42] found that trans-resveratrol did not decrease the amount of type I collagen on normal skin, and might have an antifibrogenic effect on keloid fibroblasts without adversely affecting the fibroblasts in normal skin. Kundu et al. [43] found that the suppression of COX-2 expression by blocking the activation of MAPKs and AP-1 may also represent a possible molecular mechanism for previously reported anti-tumor promoting effects of trans-resveratrol on mouse skin carcinogenesis.

It is also important to note that, after peeling, patients report stinging and increased sensibility due to the aggressive effects of acid on skin [44]. The beneficial effects of trans-resveratrol on these symptoms could be extrapolated to individuals who present with sensitive skin, a common condition in the general population, and especially in European countries [45].

The present study makes an important contribution to the dermatological treatment of chemical peeling by demonstrating the positive effects of curcumin and trans-resveratrol on the rejuvenation of photoaged skin. Not only was transresveratrol effective in increasing the thickness of the dermis and epidermis, but it is also colorless, and as such, has an advantage over curcumin, whose orangeyellow color may discourage its use for esthetic reasons.

\section{Conclusions}

Topical treatment with trans-resveratrol increased epidermal and dermal thickness. Treatment with a formulation containing curcumin, either alone or in combination with superficial chemical peeling, led to increased dermal, but not 
epidermal, thickness. The increased epidermal thickness may reflect greater skin vitality, although this was not directly evaluated. The increase in dermal thickness may be attributed to greater collagen production, which may increase skin firmness and elasticity, and lead to skin rejuvenation as well as wrinkle reduction.

Therefore, in addition to having anti-aging properties, topical formulations containing curcumin or trans-resveratrol may contribute to the treatment of skin conditions. Nevertheless, the findings obtained from animal models in the present study must still be confirmed by human trials involving medium and deep peeling in addition to superficial procedures.

In conclusion, given the painful symptoms experienced by several patients in the post-peeling period, especially after deep chemical peeling, and the possible incidence of scars or blemishes, the study of topical treatments for these issues is of great value to clinical practice.

\section{References}

[1] Velasco, M.V.R., Okubo, F.R., Ribeiro, M.E., Steiner, D. and Bedin, V. (2004) Rejuvenescimento da pele por peeling químico: enfoque no peeling de fenol [Skin Peel Rejuvenation: Focus on Phenol Peeling]. Anais Brasileiros de Dermatologia, 79, 91-99. https://doi.org/10.1590/S0365-05962004000100011

[2] Han, S.H., Kim, H.J., Kim, S.Y., Kim, Y.C., Choi, G.S. and Shin, J.H. (2011) Skin Rejuvenating Effects of Chemical Peeling: A Study in Photoaged Hairless Mice. International Journal of Dermatology, 50, 1075-1082. https://doi.org/10.1111/j.1365-4632.2010.04712.x

[3] Ganceviciene, R., Liakou, A.I., Theodoridis, A., Makrantonaki, E. and Zouboulis, C.C. (2012) Skin Anti-Aging Strategies. Dermato-Endocrinology, 4, 308-319. https://doi.org/10.4161/derm.22804

[4] Osses, M.S., Ramırez, I.G.H. and Novell, M.M. (2010) Efectividad y seguridad de 5-fluorouracilo asociado a peeling de acido glucolico em El tratamiento de queratosis actInicas multiple [Effectiveness and Safety of 5-Fluorouracil Associated with Peeling of Glycolic Acid in the Treatment of Multiple Keratoses Actica]. Piel, 25, 4-8. https://doi.org/10.1016/j.piel.2009.08.001

[5] Monteiro, E.D.O. (2008) Anestésicos tópicos (Topical anesthetics). Revista Brasileira de Medicina, 65, 12-18.

[6] Visscher, M.O. and Pan, B.S. (2013) Update on Techniques for the Quantitation of Facial Skin Characteristics. Facial Plastic Surgery Clinics of North America, 21, 7-19. https://doi.org/10.1016/j.fsc.2012.10.002

[7] Heng, M.C. (2013) Signaling Pathways Targeted by Curcumin in Acute and Chronic Injury: Burns and Photo-Damaged Skin. International Journal of Dermatology, 52, 531-543. https://doi.org/10.1111/j.1365-4632.2012.05703.x

[8] Silva Filho, C.R.M., Souza, A.G., Conceição, M.M., Silva, T.G., Silva, T.M.S. and Ribeiro, A.P.L. (2009) Avaliação da bioatividade dos extratos de cúrcuma (Curcuma longa L., Zingiberaceae) em Artemia salina e Biomphalaria glabrata [Evaluation of the Bioactivity of the Extracts of Turmeric (Curcuma longa L., Zingiberaceae) in Artemia salina and Biomphalaria glabrata]. Brazilian Journal of Pharmacognosy, 19, 919-923. http://www.scielo.br/pdf/rbfar/v19n4/22.pdf

[9] Lin, C.L. and Lin, J.K. (2008) Curcumin: A Potential Cancer Chemopreventive Agent through Supressing NF-kB Singnaling. Journal of Cancer Molecules, 4, 11-16. 
[10] Aggarwal, B.B., Kumar, A. and Bharti, A.C. (2003) Anticancer Potential of Curcumin: Preclinical and Clinical Studies (Review). Anticancer Research, 23, 363-398.

[11] Hamzah, M.M. (2011) Evaluation of Topical Preparations Containing Curcuma, Acacia and Lupinus Extracts as an Antiinflammatory Drugs. International Journal of Applied Research in Natural Products, 4, 19-23.

[12] Huang, M.T., Ma, W., Yen, P., Xie, J.G., Han, J., Frenkel, J., Grunberger, D. and Conney, A.H. (1997) Inhibitory Effects of Topical Application of Low Doses of Curcumin on 12-O-Tetradecanoylphorbol-13-Acetate-Induced Tumor Promotion and Oxidized DNA Bases in Mouse Epidermis. Carcinogenesis, 18, 83-88. https://doi.org/10.1093/carcin/18.1.83

[13] Kumar, A., Dhawan, S., Hardegen, N.J. and Aggarwal, B.B. (1998) Curcumin (Diferuloylmethane) Inhibition of Tumor Necrosis Factor (TNF)-Mediated Adhesion of Monocytes to Endothelial Cells by Suppression of Cell Surface Expression of Adhesion Molecules and of Nuclear Factor-kB Activation. Biochemical Pharmacology, 55, 775-783. https://doi.org/10.1016/S0006-2952(97)00557-1

[14] Okunieff, P., Xu, J., Hu, D., Liu, W., Zhang, L., Morrow, G., Pentland, A. and Ryan, J.L., Ding, I. (2006) Curcumin Protects against Radiation-Induced Acute and Chronic Cutaneous Toxicity in Mice and Decreases MRNA Expression of Inflammatory and Fibrogenic Cytokines. International Journal of Radiation Oncology, Biology, Physics, 65, 890-898. https://doi.org/10.1016/j.ijrobp.2006.03.025

[15] Sikora, E., Scapagnin, G. and Barbagallo, M. (2010) Curcumin, Inflammation, Ageing and Age-Related Diseases. Immunity \& Ageing, 7, 1-4. https://doi.org/10.1186/1742-4933-7-1

[16] Patel, N.A., Patel, N.J. and Patcl, R.P. (2009) Design and Evaluation of Transdermal Drug Delivery System for Curcumin as an Anti-Inflammatory Drug. Drug Development and Industrial Pharmacy, 35, 234-242.

https://doi.org/10.1080/03639040802266782

[17] Donnelly, L.E., Newton, R., Kennedy, G.E., Fenwick, P.S., Leung, R.H.F., Ito, K., Russell, R.E.K. and Barnes, P.J. (2004) Anti-Inflammatory Effects of Resveratrol in Lung Epithelial Cells: Molecular Mechanisms. American Journal of PhysiologyLung Cellular and Molecular Physiology, 287, L774-L783. https://doi.org/10.1152/ajplung.00110.2004

[18] Bode, A.M. and Dong, Z. (2000) Signal Transduction Pathways: Targets for Chemoprevention of Skin Cancer (REVIEW). The Lancet Oncology, 1, 182-188. https://doi.org/10.1016/S1470-2045(00)00029-2

[19] Malhotra, A., Nair, P. and Dhawan, D.K. (2010) Modulatory Effects of Curcumin and Resveratrol on Lung Carcinogenesis in Mice. Phytotherapy Research, 24, 12711277. https://doi.org/10.1002/ptr.3087

[20] Villaflores, O.B., Chen, Y.J., Chen, C.P., Yeh, J.M. and Wu, T.Y. (2012) Curcuminoids and Resveratrol as Anti-Alzheimer Agents. Taiwanese Journal of Obstetrics and Gynecology, 51, 515-525. https://doi.org/10.1016/j.tjog.2012.09.005

[21] Bisht, K., Wagner, K.H. and Bulmer, A.C. (2010) Curcumin, Resveratrol and Flavonoids as Antiinflammatory, Cyto- and DNA-Protective Dietary Compounds. Toxicology, 278, 88-100. https://doi.org/10.1016/j.tox.2009.11.008

[22] Mohammadi-Bardbori, A., Bengtsson, J., Rannug, U., Rannug, A. and Wincent, E. (2012) Quercetin, Resveratrol, and Curcumin Are Indirect Activators of the Aryl Hydrocarbon Receptor (AHR). Chemical Research in Toxicology, 25, 1878-1884. https://doi.org/10.1021/tx300169e

[23] Wu, Y., Jia, L.L., Zheng, Y.N., Xu, X.G., Luo, Y.J., Wang, B., Chen, J.Z.S., Gao, X.H., Chen, H.D., Matsui, M. and Li, Y.H. (2012) Resveratrate Protects Human Skin from 
Damage Due to Repetitive Ultraviolet Irradiation. Journal of the European Academy of Dermatology, 27, 345-350. https://doi.org/10.1111/j.1468-3083.2011.04414.x

[24] Juškait, V., Ramanauskien, K. and Briedis, V. (2015) Design and Formulation of Optimized Microemulsions for Dermal Delivery of Resveratrol. Evidence-Based Complementary and Alternative Medicine, 2015, Article ID: 540916. https://doi.org/10.1155/2015/540916

[25] Abla, M.J. and Banga, A.K. (2013) Quantification of Skin Penetration of Antioxidants of Varying Lipophilicity. International Journal of Cosmetic Science, 35, 19-26. https://doi.org/10.1111/j.1468-2494.2012.00728.x

[26] Alonso, C., Martí, M., Martínez, V., Rubio, L., Parra, J.L. and Coderch, L. (2013) Antioxidant Cosmeto-Textiles: Skin Assessment. European Journal of Pharmaceutics and Biopharmaceutics, 84, 192-199. https://doi.org/10.1016/j.ejpb.2012.12.004

[27] Ravagnan, G., De-Filippis, A., Cartenì, M., De-Maria, S., Cozza, V., Petrazzuolo, M., Tufano, M.A. and Donnarumma, G. (2013) Polydatin, A Natural Precursor of Resveratrol, Induces $\beta$-Defensin Production and Reduces Inflammatory Response. Inflammation, 36, 26-34. https://doi.org/10.1007/s10753-012-9516-8

[28] (2012) Guidelines for Chemical Peeling in Japan (3rd Edition). Journal of Dermatology, 39, 321-325.

[29] Noronha, L., Fiqueroa, M.C., Tamanini, P.R. and Graf, R. (2005) Neocolagenização induzida pelo resurfacing com laser erbium: YAG isolado e associado a lifting cutâneo: Estudo morfométrico comparativo em ratos (Neo-Collagenation Induced by Resurfacing with Erbium: YAG Laser Isolated and Associated with Skin Lift: Comparative Morphometric Study in Rats). Jornal Brasileiro de Patologia e Medicina Laboratorial, 41, 335-340. https://doi.org/10.1590/S1676-24442005000500008

[30] Rodrigues, L.H.T. and Maia Campos, P.M.B.G. (2002) Comparative Study of the Effects of Cosmetic Formulations with or without Hydroxy Acids on Hairless Mouse Epidermis by Histopathologic, Morphometric, and Stereologic Evaluation. Journal of Cosmetic Science, 53, 269-282.

[31] Yokomizo, V.M.F., Benemod, T.M.H., Chisaki, C. and Benemond, P.H. (2013) Chemical Peels: Review and Practical Applications. Surgical And Cosmetic Dermatology, 5, 5868.

[32] Song, J.Y., Kang, H.A., Kim, M.Y., Park, Y.M. and Kim, H.O. (2004) Damage and Recovery of Skin Barrier Function after Glycolic Acid Chemical Peeling and Crystal Microdermabrasion. Dermatologic Surgery, 30, 390-394.

[33] Gonçalves, G.M.S., Silva, G.H., Barros, P.P., Srebernich, S.M., Shiraishi, C.T.C., Camargos, V.R. and Lasca, T.B. (2015) Use of Curcuma longa in Cosmetics: Extraction of Curcuminoid Pigments, Development of Formulations, and in Vitro Skin Permeation Studies. Brazilian Journal of Pharmaceutical Sciences, 50, 885-893. https://doi.org/10.1590/S1984-82502014000400024

[34] Panchatcharam, M., Miriyala, S., Gayathri, V.S. and Suguna, L. (2006) Curcumin Improves Wound Healing by Modulating Collagen and Decreasing Reactive Oxygen Species. Molecular and Cellular Biochemistry, 290, 87-96. https://doi.org/10.1007/s11010-006-9170-2

[35] Kulac, M., Aktas, C., Tulubas, F., Uygur, R., Kanter, M., Erboga, M., Ceber, M., Topcu, B. and Ozen, O.A. (2013) The Effects of Topical Treatment with Curcumin on Burn Wound Healing in Rats. Journal of Molecular Histology, 44, 83-90. https://doi.org/10.1007/s10735-012-9452-9

[36] Prakash, L. and Majeed, S. (2003) Multifunctional Ingredients: The Novel Face of Natural. Cosmetics \& Toiletries, 118, 41-47.

[37] Henrotin, Y., Clutterbuckz, A.L., Allaway, D., Lodwig, E.M., Harris, P., Mathy- 
Hartert, M., Shakibaei, M. and Mobasheri, A. (2010) Biological Actions of Curcumin on Articular Chondrocytes. Osteoarthritis and Cartilage, 18, 141-149. https://doi.org/10.1016/j.joca.2009.10.002

[38] Mallmann, C.M., Kümmel, L.M.S. and Rosa, N.B.S. (2012) Ação da Curcuma longa no processo de envelhecimento (Curcuma Longa Action in the Aging Process). Centro Universitário Filadélfia, TANTASP, Porto Alegre.

[39] Masaki, H. (2010) Role of Antioxidants in the Skin: Anti-Aging Effects. Journal of Dermatological Science, 58, 85-90. https://doi.org/10.1016/j.jdermsci.2010.03.003

[40] Li, P., Liang, M., Zhu, Y., Gong, Y.Y., Wang, Y., Heng, D. and Lin, L. (2014) Trans-Resveratrol Inhibits Collagen I Synthesis by Suppressing IGF-1R Activation in Intestinal Fibroblasts. World Journal of Gastroenterology, 20, 4648-4661. https://doi.org/10.3748/wjg.v20.i16.4648

[41] Garcia, P., Schmiedlin-Ren, P., Mathias, J.S., Tang, H., Christman, G.M. and Zimmermann, E.M. (2012) Resveratrol Causes Cell Cycle Arrest, Decreased Collagen Synthesis, and Apoptosis in Rat Intestinal Smooth Muscle Cells. American Journal of Physiology — Gastrointestinal and Liver Physiology, 302, G326-G335. https://doi.org/10.1152/ajpgi.00083.2011

[42] Ikeda, K., Torigoe, T., Matsumoto, Y., Fujita, T., Sato, N. and Yotsuyanagi, T. (2013) Trans-Resveratrol Inhibits Fibrogenesis and Induces Apoptosis in Keloid Fibroblasts. Wound Repair and Regeneration, 21, 616-623. https://doi.org/10.1111/wrr.12062

[43] Kundu, J.K., Shin, Y.K., Kim, S.H. and Surh, Y.J. (2006) Resveratrol Inhibits Phorbol Ester-Induced Expression of COX-2 and Activation of NF-kB in Mouse Skin by Blocking IkB Kinase Activity. Carcinogenesis, 27, 1465-1474. https://doi.org/10.1093/carcin/bgi349

[44] Berardesca, E., Cameli, N., Primavera, G. and Carrera, M. (2006) Clinical and Instrumental Evaluation of Skin Improvement after Treatment with a New 50\% Pyruvic Acid Peel. Dermatologic Surgery, 32, 526-531.

[45] Escalas-Taberner, J., González-Guerra, E. and Guerra-Tapia, A. (2011) Sensitive Skin: A Complex Syndrome. Actas Dermo-Sifiliográficas, 102, 563-571. https://doi.org/10.1016/j.ad.2011.04.011

\section{Scientific Research Publishing}

\section{Submit or recommend next manuscript to SCIRP and we will provide best service for you:}

Accepting pre-submission inquiries through Email, Facebook, LinkedIn, Twitter, etc. A wide selection of journals (inclusive of 9 subjects, more than 200 journals)

Providing 24-hour high-quality service

User-friendly online submission system

Fair and swift peer-review system

Efficient typesetting and proofreading procedure

Display of the result of downloads and visits, as well as the number of cited articles

Maximum dissemination of your research work

Submit your manuscript at: http://papersubmission.scirp.org/

Or contact jcdsa@scirp.org 